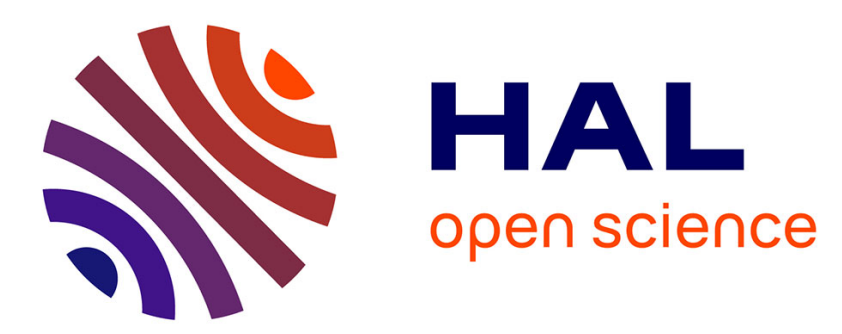

\title{
Silicon carbonitrides - A novel class of materials
}

H. Schönfelder, F. Aldinger, R. Riedel

\section{To cite this version:}

H. Schönfelder, F. Aldinger, R. Riedel. Silicon carbonitrides - A novel class of materials. Journal de Physique IV Proceedings, 1993, 03 (C7), pp.C7-1293-C7-1298. 10.1051/jp4:19937199 . jpa-00251832

\section{HAL Id: jpa-00251832 https://hal.science/jpa-00251832}

Submitted on 1 Jan 1993

HAL is a multi-disciplinary open access archive for the deposit and dissemination of scientific research documents, whether they are published or not. The documents may come from teaching and research institutions in France or abroad, or from public or private research centers.
L'archive ouverte pluridisciplinaire HAL, est destinée au dépôt et à la diffusion de documents scientifiques de niveau recherche, publiés ou non, émanant des établissements d'enseignement et de recherche français ou étrangers, des laboratoires publics ou privés. 


\title{
Silicon carbonitrides - A novel class of materials
}

\author{
H. SCHÖNFELDER, F. ALDINGER and R. RIEDEL*
}

Max-Planck-Institute of Metals Research, Laboratory for Powder Metallurgy, Institute of Materials Science, Heisenbergstr. 5, 7000 Stuttgart 80, Germany

* University of Darmstadt, Institute of Materials Science, Hilpertstr. 31, PTZ, Building D, 6100 Darmstadt, Germany

\begin{abstract}
Silicon carbonitride monoliths derived from polymer powder compacts via polymer pyrolysis represent a new class of structural ceramic materials due to the complete coalescence of the powder particles during polymer decomposition and the formation of a uniform ceramic matrix free from any grain boundaries or secondary phases. The submicron pore channel system penetrating the material can be minimized in volume by infiltration of liquid polysilazane solution or by post-HIPing so that relative densities of $96 \%$ can be reached. The monoliths are oxidation resistant up to $1600{ }^{\circ} \mathrm{C}$ in air due to the formation of a highly pure silica oxidation layer and they exhibit a creep rate of $1 \cdot 10^{-6} \mathrm{~s}^{-1}$ at $1650^{\circ} \mathrm{C}$ and $30 \mathrm{MPa}$ load. Initially $\mathrm{x}$-ray amorphous silicon carbonitride can be crystallized in nitrogen or in air to form $\mathrm{Si}_{3} \mathrm{~N}_{4} / \mathrm{SiC}$ or $\mathrm{Si}_{3} \mathrm{~N}_{4} / \mathrm{SiC} / \mathrm{C}$ nanocomposites.
\end{abstract}

\section{Experimental (fig. 1)}

Fusible polyhydridomethylsilazane $\left[\mathrm{CH}_{3} \mathrm{SiHNH}_{m}\left[\left(\mathrm{CH}_{3}\right)_{2} \mathrm{SiNH}\right]_{n}\right.$ with a molecular weight distribution of $900-1100$ is thermally crosslinked at $400{ }^{\circ} \mathrm{C}$ for $2 \mathrm{~h}$ under argon atmosphere and for $1 \mathrm{~h}$ under vacuum $\left(5 \cdot 10^{-3} \mathrm{mbar}\right)$. The resulting infusible foam is ball milled and sieved to the desired particle size distribution and then cold isostatically pressed (640 $\mathrm{MPa}$ ) to form a polymer powder compact. Subsequent heating to $1000^{\circ} \mathrm{C}$ in a quartz glass tube under argon atmosphere induces the decomposition of the polymer and the formation of monolithic silicon carbonitride [1]. In order to increase the density of the monoliths a solution of $70 \%$ polysilazane in THF can be infiltrated into the open pore channel system and pyrolysed to deposit additional matrix material. In this technique, the samples are evacuated for $30 \mathrm{~min}\left(1 \cdot 10^{-2} \mathrm{mbar}\right)$ while the solution is cooled to $-73^{\circ} \mathrm{C}$ in order to reduce the vapour pressure. Then the samples are put on top of the viscous 
solution and start submerging while the solution is heated to room temperature. After $1 \mathrm{~h}$ of infiltration the samples are taken out of the solution and pyrolysed as before. Alternatively, silicon carbonitride pyrolysed to $800^{\circ} \mathrm{C}$ only is encapsulated in glass under vacuum $\left(1 \cdot 10^{-2} \mathrm{mbar}\right)$ and hot isostatically pressed at $200 \mathrm{MPa}$ and $1100^{\circ} \mathrm{C}$ for $1 \mathrm{~h}$.

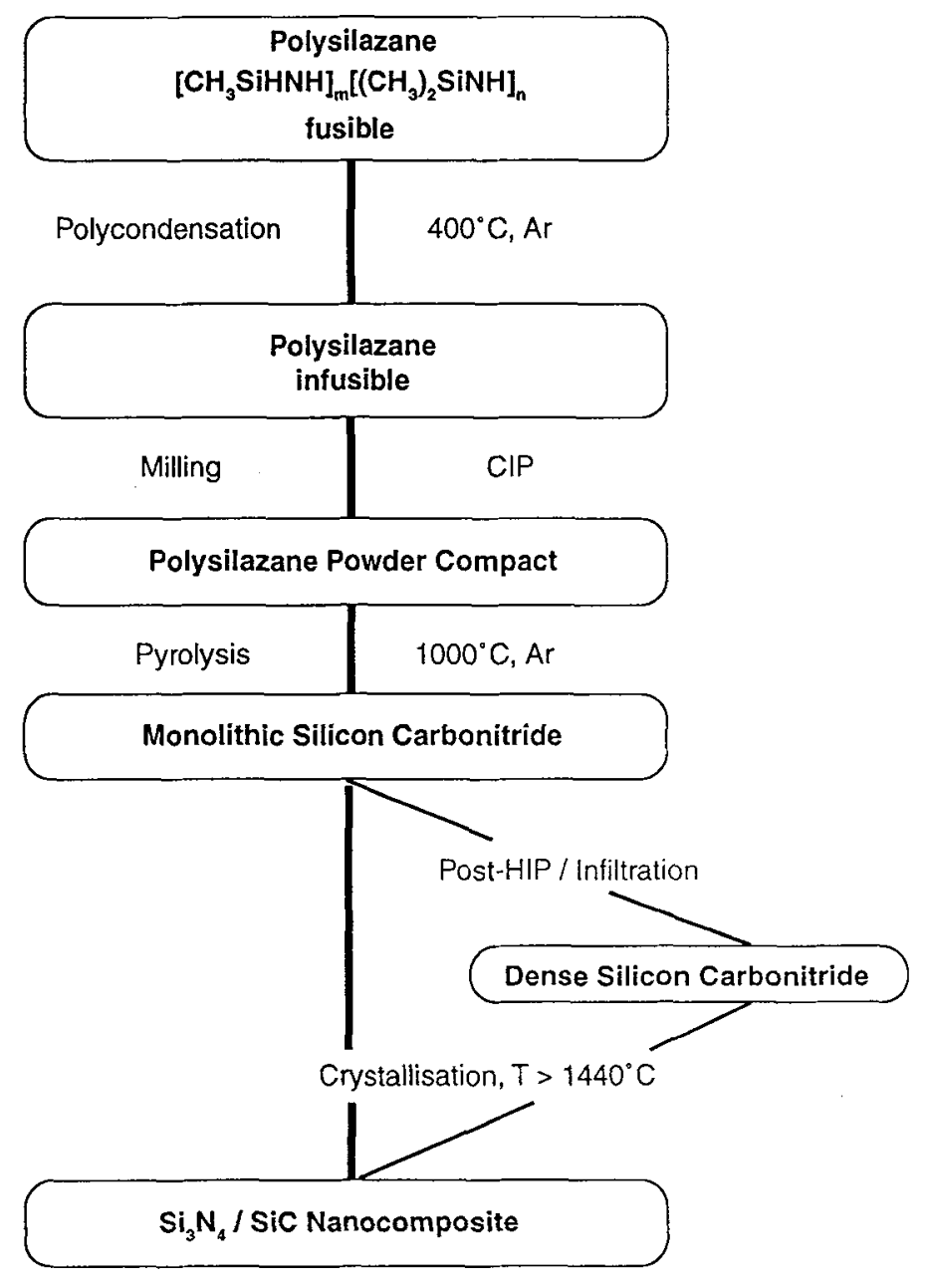

Fig.1 : Schematic experimental procedure for the preparation of silicon-based nonoxide ceramics derived from polysilazane. 


\section{Results and Discussion}

Densification of the novel material starts at the polymer powder stage. Analogously to ceramic powder, polysilazane powder can be cold isostatically pressed to tough greenbodies. However, extremely high green densities of $84 \%$ can be reached due to plastic deformation of the powder particles and no binders are necessary. During pyrolysis the polysilazane is decomposed to form $x$-ray amorphous, non-stoichiometric silicon carbonitride of the formal composition $\mathrm{Si}_{3+\mathrm{x}} \mathrm{N}_{4} \mathrm{C}_{\mathrm{x}+\mathrm{y}}$ $(x, y \geq 0)$. This ceramization process is caused by the release of methane and hydrogen between 600 and $800^{\circ} \mathrm{C}$ and by simultaneous particle coalescence forming a uniform ceramic matrix which is penetrated by a continuous submicron pore channel system (fig. 2). Relative sample densities increase up to $93 \%$ and also larger parts stand the linear shrinkage of $27 \%$ without crack formation (fig. 3).

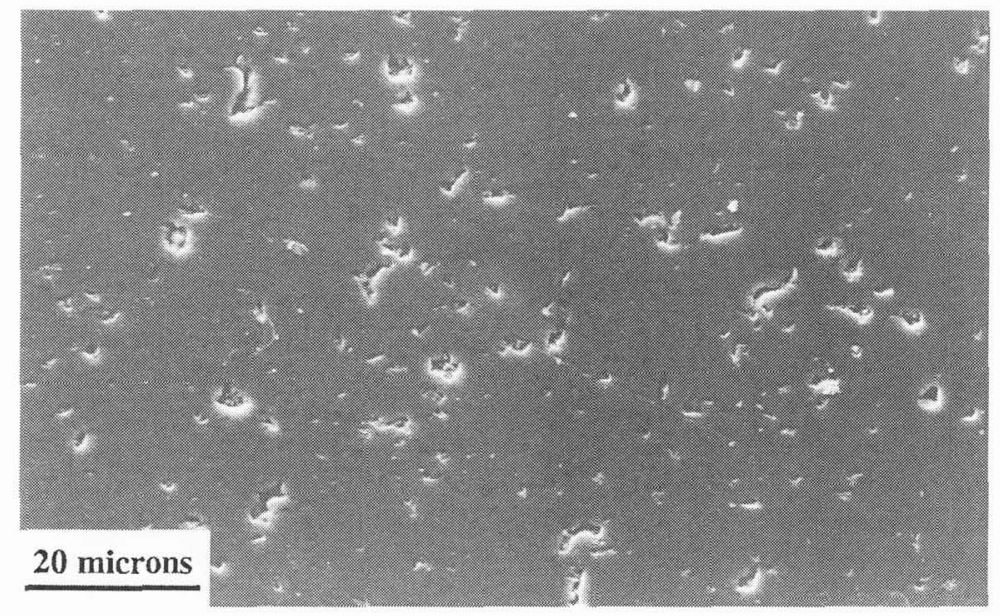

Fig. 2 : SEM micrograph of the uniform Si-C-N matrix and isolated pores interconnected by a continuous submicron pore channel system.

The coarseness of the open pore channel system can be adjusted by means of the polymer particle size distribution. A coarse powder yields a pore radius distribution maximum near 1 micron while a fine powder yields a distribution maximum at $75 \mathrm{~nm}$ (fig. 4). Densities between 88 and $93 \%$ are attainable this way. In order to further reduce the porosity the open pore channel system can effectively be infiltrated by liquid polysilazane solution which deposits additional matrix material upon pyrolysis. After three infiltrations an initial relative density of $90 \%$ can be increased to $96 \%$. 


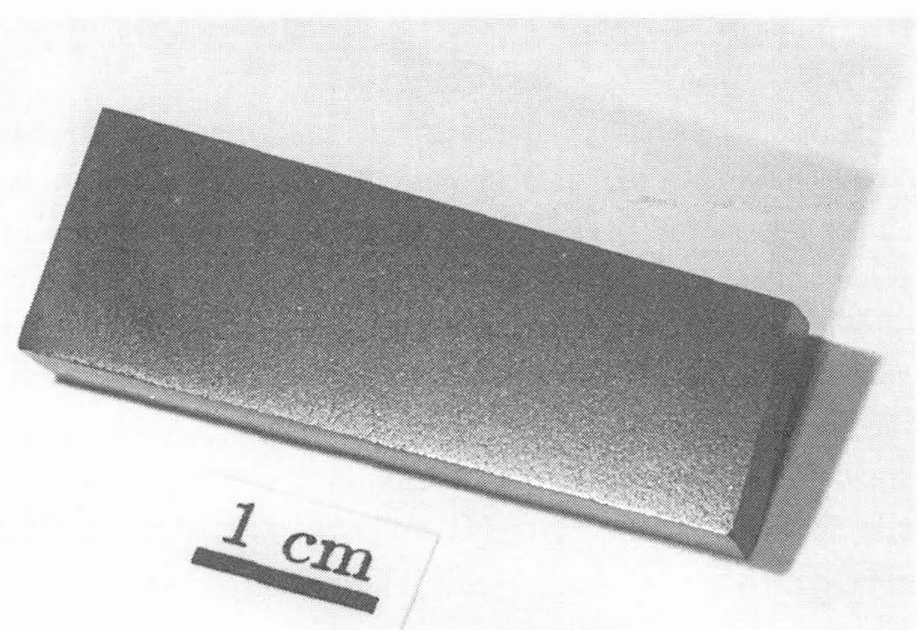

Fig. 3 : Monolithic silicon carbonitride part.

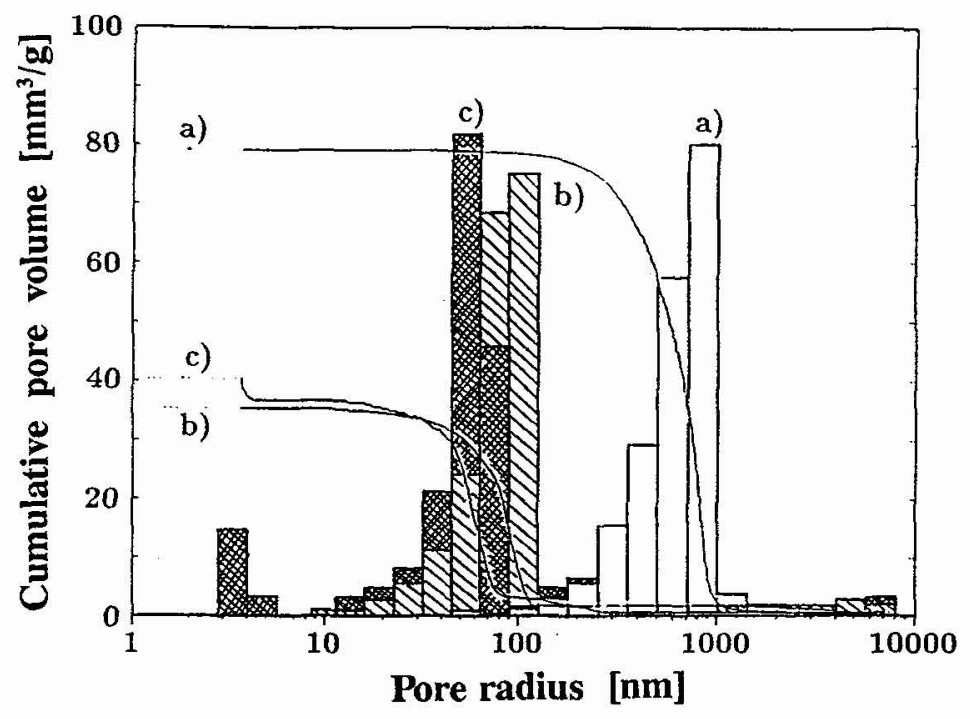

Fig. 4 : Pore radius distributions of silicon carbonitride pyrolysed from polysilazane powder with (a) coarse, (b) medium-size, and (c) fine particle size maximum.

First data on the mechanical and thermal properties show that silicon carbonitride reaches a Vickers hardness of $12 \mathrm{GPa}$ and a 4-point bending strength of $175 \mathrm{MPa}$ with maximum values of 245 and $375 \mathrm{MPa}$. Due to the absence of grain boundaries and oxidic sintering aids the creep rate is as low as $1 \cdot 10^{-6} \mathrm{~s}^{-1}$ at $1650^{\circ} \mathrm{C}$ and $30 \mathrm{MPa}$ load [2]. For the same reasons the material is highly 
oxidation resistant. Weight gains after $24 \mathrm{~h}$ of isothermal oxidation at $1000-1400{ }^{\circ} \mathrm{C}$ are below $1 \%$ and the oxidation rates are asymptotically approaching zero (fig. 5). Due to the small pore channel radii of $75-100 \mathrm{~nm}$ Knudsen flow of the air inside the pore channels becomes effective [3]. In this gas flow regime the diffusivity $D_{K}$ of oxygen increases with the square root of the temperature $T$ :

$D_{K}=\frac{4}{3} r\left(\frac{2 R T}{\pi M}\right)^{\frac{1}{2}}$

r: pore channel radius

R: gas constant

M: mass of transported species

As the rate of the initial oxidation reaction between oxygen and silicon carbonitride to form silica increases exponentially with temperature, oxygen consumption at the pore channel walls is faster than oxygen gas diffusion to the interior of the sample. Thus the pore channel mouths are preferentially thickened until they completely seal the pore channels resulting in a strong reduction of the total surface area being oxidized. Most important, however, the low diffusion coefficient of oxygen in pure silica of $10^{-6}-10^{-11} \mathrm{~cm}^{2} \mathrm{~s}^{-1}$ [4] leads to a sharp decrease of the oxidation rate especially at higher temperatures (fig. 5). At lower temperatures the transition from reaction controlled to diffusion controlled oxidation is less pronounced as it takes more than $24 \mathrm{~h}$ to be complete.

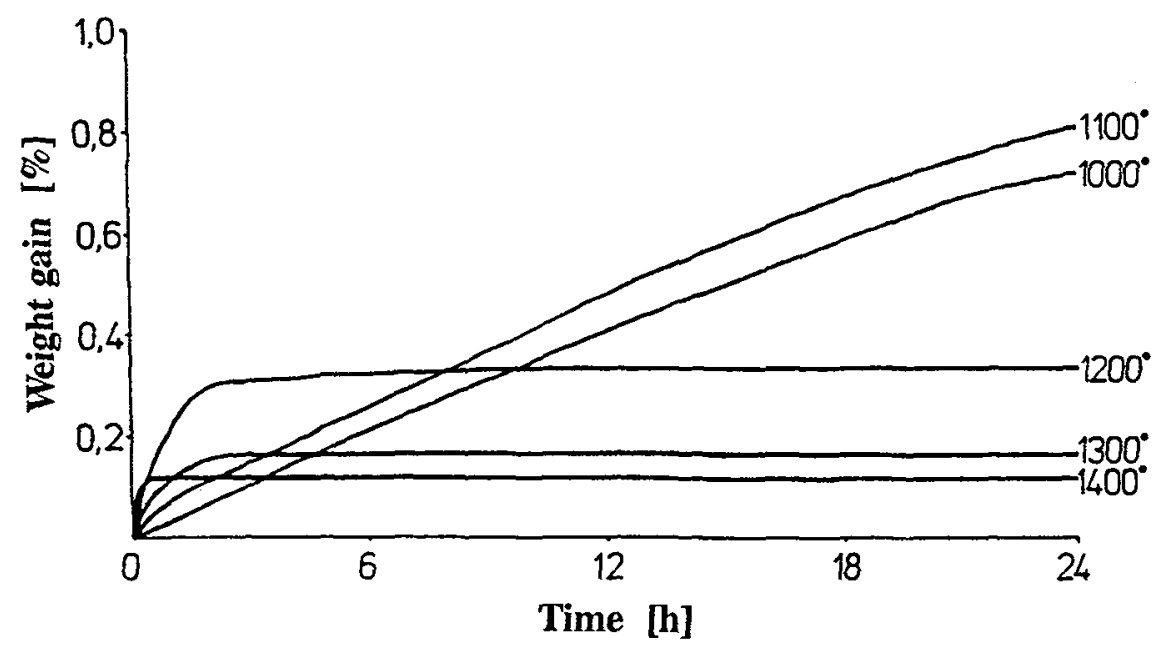

Fig. 5 : Weight gain versus time during isothermal oxidation in air. 
Within the nonstoichiometric system $\mathrm{Si}_{3+x} \mathrm{~N}_{4} \mathrm{C}_{x+y}(x, y \geq 0)$ the thermodynamically stable phases at 1 bar nitrogen pressure and $\mathrm{T} \leq 1440^{\circ} \mathrm{C}$ are $\mathrm{Si}_{3} \mathrm{~N}_{4}, \mathrm{SiC}$ and graphite. However, after heat treatment of $50 \mathrm{~h}$ at $1400^{\circ} \mathrm{C}$ the amorphous state is still retained metastable. Electron spectroscopic imaging (ESI) based on EELS shows no phase separations within a resolution of 20 angstrom and confirms the completely amorphous structure of silicon carbonitride. Above $1440^{\circ} \mathrm{C}$, some of the silicon bonded to nitrogen within the amorphous network reacts with carbon to form silicon carbide and nitrogen gas. This reaction is accompanied by a weight loss of $17 \%$ in the solid phase and a significant increase of porosity to $30 \%$. Simultaneously, the crystallisation of $\beta-\mathrm{SiC}$ and $\alpha-\mathrm{Si}_{3} \mathrm{~N}_{4}$ is induced. A totally different process takes place when amorphous silicon carbonitride is crystallized in air. Due to the formation of the highly pure silica layer by surface oxidation of the monoliths, nitrogen diffusion is inhibited. Thus no decomposition reaction and no porosity increase occurs. In contrast, sealing of the pore channel mouths by $\mathrm{SiO}_{2}$ eliminates the open porosity. Whereas at $1500^{\circ} \mathrm{C}$ the material is still largely amorphous, $\alpha-\mathrm{Si}_{3} \mathrm{~N}_{4}$ and $\alpha-\mathrm{SiC}$ start to crystallize at $1600^{\circ} \mathrm{C}$. Hence, a monolithic $\mathrm{Si}_{3} \mathrm{~N}_{4} / \mathrm{SiC} / \mathrm{C}$ nanocomposite material has been created that is oxidation resistant up to $1600^{\circ} \mathrm{C}$ in air.

\section{Conclusion}

The results exhibit that two types of materials can be processed by means of the technique described above:

1. Amorphous silicon carbonitride produced at temperatures as low as $1000^{\circ} \mathrm{C}$, and

2. $\mathrm{Si}_{3} \mathrm{~N}_{4} / \mathrm{SiC} / \mathrm{C}$ nanocomposites with an oxidation resistance of up to $1600^{\circ} \mathrm{C}$ in air.

The relative densities of up to $93 \%$ of the synthesized silicon carbonitride can be increased by liquid infiltration or post-HIPing to $96 \%$.

\section{References}

[1] R. RIEDEL, G. PASSING, H. SCHÖNFELDER, R.J. BROOK, Synthesis of Dense Silicon Based Ceramics at Low Temperatures, Nature 355 (1992) 714-717.

[2] I.-W. CHEN, private communication.

[3] F. PORZ, F. THÜMMLER, Oxidation Mechanism of Porous Silicon Nitride, J. Mater. Sci. 19 [8] (1984) 1283-1295.

[4] H.A. SCHAEFFER, Sauerstoff- und Siliciumdiffusion in silicatischen Gläsern, Habilitationsschrift, Universität Erlangen-Nürnberg (1980) 137 p. 